\title{
LA ÉTICA DE LA LIBERTAD Y REDARQUÍA: ANÁLISIS PROSPECTIVO EN CIVILIZACIONES MODERNAS
}

\author{
The ethics of liberty and webarchy: \\ prospective analysis in modern civilisations
}

ADRIÁN BARROSO RICOTE

Fecha de recepción: 2 de noviembre de 2019

Fecha de aceptación: 1 de marzo de 2020

\section{I \\ INTRODUCCIÓN}

Este artículo se centra en cómo se podría desarrollar un sistema de "justicia" global, utilizando para ello medios que se encuentran ya en la actualidad. En este caso, la finalidad es encontrar una aplicación práctica a un tema filosófico tan controvertido como puede ser la ley natural, en contraposición al sistema actual de justicia iuspositivista.

Actualmente, la justicia y la ley (positiva) vienen determinadas por los Estados. En cada país, podemos encontrarnos gran cantidad de leyes que traten un mismo tema de manera distinta. Tanto es así que, poner en común a todos los Estados y optar por una forma social que nos una más a nivel ético está cerca de ser un imposible, si eso atañe al poder del gobernante de turno.

La intención de este escrito se ve altamente influenciada por la situación de crisis en la que nos encontramos. No refiriéndose, así, a una suerte de crisis económica, sino a la crisis de valores que estamos sufriendo, que hace que nos enfrentemos más los unos a los otros, que nos hace violentos, nos incita a actuar inmoralmente y en la cual, a pesar de todo, la justicia puede que no termine aplicándose como es debido. Como, por ejemplo, en aquellas civilizaciones en las 
que, si se suma una crisis económica a una sociedad cada vez menos éticamente correcta, la situación de crisis de seguridad sería un escenario plausible muy complicado de resolver.

Tras la lectura de este artículo, puede que el lector se empiece a cuestionar si el sistema actual de justicia, en su forma, es el único sistema posible o si, por el contrario, pudieran surgir otros que garanticen también la seguridad, sin quebrantar, de manera tan acuciante, la libertad individual.

IUSNATURALISMO VS. IUSPOSITIVISMO

A lo largo de la historia, el eterno retorno del derecho natural' siempre ha puesto en debate la lucha, que ya desde Platón se planteaba, entre la ley positiva y la ley natural, es decir, entre la separación de lo moral y el derecho.

Tradicionalmente, la inexplicable interrelación entre la ley natural y la teología ha causado un gran daño a los argumentos iusnaturalistas, al establecer como necesaria una fe teológica para defender su validez, lo cual ha dado lugar a un abandono progresivo de la idea de una ley natural fundada en la razón y en la investigación racional. Consecuentemente, debido a esa interrelación, aquellos que intenten argumentar a favor de lo natural, tendrán que lidiar contra los argumentos teológicos, basados en la fe, y los iuspositivistas ${ }^{2}$.

Sin embargo, Tomás de Aquino, uno de los grandes defensores de la separación entre filosofía y teología, afirmaba que "la razón humana posee la capacidad de comprender y descubrir las leyes,

\footnotetext{
${ }^{1}$ Expresión acuñada por H. Rommen, Die ewige Wiederkhr des Naturrechts, Manchen, Hegner, 1947.

2 Es curioso como en Clásico de Poesía, uno de los libros más importantes del confucianismo (siglos XI-VII a.C.), ya se hablaba de que la naturaleza ha creado unas leyes naturales que los hombres deben seguir, aunque lo entremezcla con conceptos religiosos como "cielo" (tiān), "destino" (tiānmìng formado por los caracteres de "vida" y "cielo", usualmente interpretado como "mandato del cielo")o "civilización" (tiānxià, literalmente "bajo el cielo") (Confucio, 2014).
} 
tanto físicas como morales, del orden natural"3(Rothbard, 2009:28), a pesar de ser un hombre religioso. Otros ejem plos como el escolástico Suárez o Hugo Grocio son también representativos de esta dualidad teológica y filosófica. Es por eso que hay que dejar claro que la afirmación "existe un orden de leyes naturales accesible a la razón" no es "en sí misma", ni pro ni antirreligiosa (ibidem, 29).

Citando a Rothbard: "En la teoría de la ley natural, la ley general de la moralidad humana es un caso particular del sistema de la ley natural por el que se rigen todos los seres del universo según su propia naturaleza y fines. Es por eso que a los seres no-humanos se ven compelidos a actuar de acuerdo con los fines que les dicta su naturaleza [instinto], mientras que el hombre posee la razón para así descubrir estos fines y libertad para elegirlos.[...]

Además, se establece que para todos los seres vivientes, lo "bueno" significa aquello que satisface mejor una necesidad para ese tipo concreto de criatura. Por consiguiente, la "bondad" está referida a la naturaleza de la criatura en cuestión. Consecuentemente, por ejemplo, no juzgamos que los elefantes sean buenos porque son seres naturales o porque su naturaleza es moralmente buena, juzgamos que un elefante en concreto es bueno a la luz de lo que puede hacer de acuerdo con su naturaleza". (ibidem, pp 32-38).

En el caso de los seres humanos, será la ética de la ley natural la que establezca qué puede determinarse como bueno o malo, según le permita o le impida realizar lo que es mejor para la naturaleza humana. Es por eso que la ley natural aclara qué es mejor para el hombre o qué fines se deben perseguir, por ser los más acordes con su naturaleza y los que mejor tienden a realizarla.

Es interesante ver también la postura de Oakeshott (2001), cuya teoría dice que la práctica ${ }^{4}$ es "un conjunto de consideraciones, máximas, usos, maneras, observaciones, reglas, principios y deberes que especifican procedimientos o denotan obligaciones o deberes en relación a la conducta humana y palabras. Es una calificación de las elecciones o actuaciones morales o prudenciales, más o menos complicada, por la cual la conducta es comprendida en tér-

${ }^{3}$ Debido a esta separación, M. F. Sciacca, en "Perspectiva de la metafísica en Santo Tomás", considera que gracias a él se constituye el nacimiento de la conciencia laica.

${ }^{4}$ Para Oakeshott hay una equivalencia entre el término práctica y tradición. 
minos de procedimiento" (López Atanes, 2010:62), de lo que se puede deducir que el concepto "práctica" tiene un carácter ético de la conducta humana.

A su vez, ve la tendencia del orden extenso como una tensión entre el "mundo de lo que es aquí y ahora" y el "mundo de lo que debe ser", atendiendo a que esa aproximación al segundo mundo sólo puede ser viable si se da una tradición racional, es decir, que solo aquellas tradiciones racionales son las que garantizarían el orden social para que cada vez haya menos diferencia entre un mundo y otro. Es por eso que llega finalmente a la contradictoria afirmación "mantener es siempre cambiar" (ibidem, pp 78).

Es normal que, tras esto, algunos autores como Hayek vean el orden extenso como algo entre el instinto ${ }^{5}$ y la razón, aludiendo así a que "si pretendiéramos aplicar las rígidas pautas de conducta propias del microcosmos al macrocosmos pondríamos en peligro a ese segundo tipo de orden. Y si, a la inversa, pretendiéramos aplicar la normativa propia del orden extenso a esas agrupaciones más reducidas, acabaríamos con la misma cohesión que las aglutina" (F.A. Hayek, 2011:49).

Tras los diferentes puntos de vista anteriores, a través de los cuales no se llega a una conclusión filosófica aceptada comúnmente, se nos plantea finalmente si toda esta lucha entre razón y tradición, tradición racional y tradición pasional, razón y pasión, etc. es realmente el debate de fondo entre el lusnaturalismo e luspositivismo o si, en verdad, es la respuesta a otra lucha distinta, la del libre albedrío frente al Estado, sobre si puede darse un orden social sin la presencia de un Estado en materia de justicia.

Algunos autores anarco-capitalistas como Hans-Hermann Hoppe abogan a una posible tendencia natural al iuspositivismo ${ }^{6}$. Dicho de otro modo, ante los malos comportamientos surgirían

\footnotetext{
${ }^{5}$ Hayek trata de indiferente los términos instinto y tradición aunque para Oakeshott son totalmente distintos.

${ }^{6}$ Generalmente se asocia a Hoppe con el iusnaturalismo, debido a la "tendencia natural" a la que alude. Sin embargo, mi interpretación le sitúa en el iuspositivismo, al emplear la falacia ad verecundiam del rey justo. Mi interpretación de iusnaturalismo tendería a excluir todo argumento falaz, aunque si siempre la tendencia natural realmente es hacer caso al argumento de "es así porque lo dice el rey justo" de manera exógena, podría considerarse entonces como pro-ley natural dicha teoría de Hoppe.
} 
jueces informales los cuales ganarían cada vez más reputación en base a tener unos valores éticos superiores. Dichas personas actuarían como jueces iuspositivistas, es decir, impondrían sus propias leyes (o código ético) al resto de personas, con lo que el orden extenso tendería a aquello que debería corresponderle en materia de lo moral. Sin embargo, dichos jueces pueden ser altamente corruptibles y, por lo tanto, ser "inmunes" al castigo por actuar mal. Dicha estructura de la sociedad correspondería bien con la creación natural del rey justo, el cual era el encargado de impartir justicia, precisamente, por tener unos valores éticos fuertes. Si dicho juez actuase inmoralmente, algo inevitable debido al relativismo moral (lo que unos consideran como bueno-malo otros puede que no lo consideren igual), es altamente probable que surjan inestabilidades en el orden extenso, como bien se ha visto a lo largo de la historia (Hans-Hermann Hoppe, 1995: 94-121).

Habría que matizar que, en lo correspondiente a lo moral, no nos referimos únicamente a lo que consideremos como bueno o malo, a un código de delitos morales, sino también en la pena que se establece cuando se ha cometido un acto inmoral. De esta manera, se podría considerar que robar está mal, pero también que el castigo de cortar las manos al ladrón sea inmoral y tacharlo de excesivo. De ahí, que surjan las ideas de la pena del ojo por ojo, dos ojos por ojo, etc. Eso nos lleva a pensar si este tipo de castigos son buenos o malos y si se tendería también, de manera natural, hacia un castigo moral comúnmente aceptado por todos (y, por lo tanto, el juez iuspositivista debería estudiar dicha tendencia) o si cada uno tiende a imponer su propio castigo social con los recursos que uno mismo dispone para ello?.

Con ello se quiere hacer entender que, en lo referente al código ético del orden extenso y cómo tienda éste hacia lo que debería ser en cada momento histórico, hace que varíe tanto en el código en sí (lo que es comúnmente aceptado como bueno-malo), la pena o castigo moral, así como la forma en la que tiende a materializarse dicha tendencia (monarquía, democracia, dictadura, etc). Es decir,

7 Sería conveniente releer esta frase una vez acabado de leer el artículo completo para saber exactamente el matiz que se le quiere dar. 
que el hecho de que ciertos autores estén a favor de una determinada forma $u$ otra de iuspositivismo se ve altamente influenciado por las características propias de cada momento histórico. Tal vez, tal y como predica Hoppe, el rey justo puede que surja de manera natural. Incluso Rousseau, el cual alabó siempre lo natural, propuso la forma de democracia directa como único camino hacia la libertad del ser humano (aunque, en tiempos de Aristóteles, se viese como impensable una democracia con más de cien mil personas). Cada forma viene asociada con un contexto histórico determinado, con lo cual, puede que en un futuro surjan modelos de sociedad totalmente distintos que ahora consideramos imposibles o distópicos.

Finalmente, es de conveniencia destacar que, a la vez que se puede dar una variación natural en la forma iuspositivista, el libre albedrío se podría canalizar también, en la sociedad, de manera estructurada con una evolución en su forma, es decir, podría establecerse una anarquía auto-controlada en cuestiones de lo moral, superando así la tradicional falacia ad verecundiam ${ }^{8}$ y ad populum ${ }^{9}$, propias del iuspositivismo. Como consecuencia, se tendería a una forma en la que cada individuo juzgue lo bueno y lo malo sin hacer referencia a leyes dictadas por otros (o por la mayoría) y así argumentar su respuesta sobre lo moral con lo que realmente se piense o sienta a nivel individual.

\section{III EL CÓDIGO ÉTICO UTILIZADO}

El código ético que se ha considerado para la realización de este artículo ha sido, con ciertos matices, el que propone Rothbard en La Ética de la Libertad. Evidentemente, puede que no todo el mundo

\footnotetext{
8 La falacia ad verecundiam consiste en defender algo como verdadero porque, quien es citado en el argumento, tiene autoridad en la materia. Referido a monarquías, dictaduras.

${ }^{9}$ La falacia ad populum implica responder a un argumento o a una afirmación refiriéndose a la supuesta opinión que tiene la gente en general, en lugar de al argumento por sí mismo. Principalmente referenciado en sociedades democráticas.
} 
tome como bueno aquello que se propone en este epígrafe, pero a fin de cuentas, es a ello a lo que se expone el iusnaturalismo, a la variación continua de lo moral y su tendencia natural hacia lo que debe de ser. Dichos derechos naturales, hacia los que tendemos, se considerarían principios absolutos, accesibles a la razón, relativos a la especie humana con independencia de la raza, religión, color o sexo.

La teoría que vamos a desarrollar no se centrará tanto en la libre voluntad del hombre para adoptar ideas y valores, sino en las limitaciones de libertad de acción o libertad para convertir dichas ideas en hechos reales en el mundo.

Cuando hablamos de limitaciones en la libertad de acción, no nos referimos a las limitaciones de poder realizar una acción en base a las leyes de la física (ej.: "no puedo respirar bajo el agua ergo no soy libre"), sino a los límites que impone la misma sociedad a la propia sociedad.

De este modo se trazará una libertad individual de actuación para el hombre, pero limitada a la libertad individual de otros. Por eso nos basaríamos en el siguiente principio fundamental para garantizar la libertad social: cada persona tiene posesión de sí mismo, de su tiempo y de lo que ha adquirido ya sea por medio de la transformación, intercambio o la donación voluntaria. Debido a esto, es normal que Rothbard considere que libertad y derecho de propiedad sean indisolubles, y que cualquier atentado contra la propiedad es un ataque directo contra la libertad individual de cada uno, ya que se priva al hombre de las condiciones para ejercer realmente sus derechos. Por lo tanto, será considerado como delincuente aquel individuo que emplea la coacción o ataca a una persona o a la propiedad producida por ella.

La concepción que toma Rothbard sobre la propiedad privada, basada en la teoría de la propiedad lockeana, se divide en dos apartados: la derivada de los intercambios intrapersonales y la derivada de los interpersonales (ambos aludiendo a la metáfora robinsoniana del hombre solitario en una isla desierta que más tarde se encuentra con otro hombre $)^{10}$.

10 Para un desarrollo más extenso léase el capítulo 6 de La ética de la Libertad de Rothbard. 
A continuación se expondrá brevemente el código ético base sobre el cual se desarrollará el apartado siguiente ${ }^{11}$ :

- Defensa personal y castigo: el axioma fundamental de la teoría libertaria es que nadie puede amenazar o cometer un acto de violencia (agresión) en contra de otra persona o propiedad de otras personas. A la hora de responder de manera inmediata a dichas manifestaciones de violencia, se podría tender hacia el principio tolstoyano de no agresión o hacia la justificación de la defensa personal. Una vez que acaba la inmediatez del acto, la naturaleza del contexto cambiaría y se hablaría más de castigo. Como mencionamos anteriormente, el relativismo moral también afecta al castigo, es por ello que la sociedad podría derivar en diversas formas de castigo social, como el ojo por ojo, dos ojos por ojo, multas, arrestos, etc.

- Cumplimiento de contratos: en sí, un contrato es un intercambio voluntario (material o inmaterial) entre 2 partes, es decir, A paga a $B$ a cambio de un bien o un servicio. Sin embargo, el dilema aparece cuando ese contrato voluntario entra en contradicción con otro contrato voluntario, es decir, si A contrata a B para desempeñar un trabajo con unas pautas determinadas y una persona $C$ contrata a $B$ para que no cumpla algunas de esas pautas. En este caso, se podría decir que tanto $A$ como $C$ son los damnificados de dichos intercambios, puesto que solo se cumplirá uno de los dos. Por lo tanto, el delincuente moral sería, en este caso, la persona B, la cual, si acepta el contrato con C, incumplirá a su vez el contrato con A.

- Boicot: el boicot en sí consiste en persuadir a los demás a la hora de poner una serie de filtros a una serie de variables. Generalmente, es asociado con la marginación, pero, en realidad, establecer una serie de filtros a las cosas y personas forma parte intrínseca de la sociedad. Si no filtrásemos, sería imposible físicamente establecer relación con toda la humanidad o elegir todas las opciones a la vez, a la hora de satisfacer una

11 Ya que el código ético en sí no es el punto destacado de este artículo, para un desarrollo más amplio véase La Ética de la Libertad de Rothbard y para casuísticas más visuales Defending the indefendable de Walter Block. 
necesidad, entre un abanico amplio de opciones. Si A obligase coactivamente a $\mathrm{B}$ a elegir una opción que no habría tomado si no fuese por dicha coacción, se consideraría que A ha vulnerado el derecho de boicot/filtrado propio de $\mathrm{B}$, el cual es el único que sabe qué es lo que realmente quiere.

- Privacidad: solemos asociar el concepto privacidad a toda información sobre nuestra persona que elegimos no hacer pública, es decir, que mantenemos en secreto con nosotros mismos o con un reducido número de personas. De esta manera, se podría decir que nosotros perdemos privacidad en la misma cuantía que nosotros cedemos información personal.

Estos últimos años, con la crecida del uso de Internet, ha aumentado exponencialmente la información personal que cedemos. Ahora la gente está empezando a concienciarse sobre si es conveniente o no hacer pública tanta información que atañe a su persona. Es por ello que la misma competencia tiende a adaptarse conforme a las necesidades de privacidad de dicha información, cuya concepción moral es muy volátil.

Además, para que se dé el orden social, es inevitable que tengamos que perder información nuestra con algunos actos que realizamos. Cuando una persona A compra una serie de productos a una persona $B$, es evidente que $B$ está obteniendo una información de los productos que está vendiendo, e incluso quiera personalizar dicha información y asociarla a la persona $A$. Esto ocurriría en el caso de que A fuese un comprador habitual o cediese, de forma voluntaria, su identidad personal para futuros descuentos, personalización de la compra u otra serie de fines.

Evidentemente, el vendedor B puede premiar o sancionar la cesión o no de dicha información por parte del consumidor $A$ en forma de subidas o bajadas de precios de los bienes comprados. Incluso se puede dar el caso en el que, si no presentas un documento acreditativo, no te vendan directamente el producto.

- Libertad de expresión: el ser humano tiene el derecho de expresarse libremente, a expensas de ser juzgado por los demás por lo que dice. Sin embargo, hay algunas situaciones en las que dicha libertad de expresión se ve no solo limitada por los 
contratos voluntarios que realizamos, sino también por las normas de actuación que dicte el dueño o responsable de una propiedad privada.

- Los niños, ancianos, personas dependientes: dichos agentes tienden a crear disrupciones en el código ético de la "libertad", aplicándoseles otra serie de leyes positivas y/o naturales a los cuales no entraremos en detalles en este escrito.

- Los animales: el código ético de la "libertad" puede también atender a la ampliación del concepto de los derechos para abarcar a los animales. Sin entrar en un análisis exhaustivo, dicha alteración del código de ético sería por parte de los humanos hacia los animales, y no viceversa.

En dicho código habría que matizar que, la postura que mantiene Reinach en cuanto a la concepción de la "intención”, es mucho más acertada y, por lo tanto, debería tenerse en cuenta también a la hora de establecer la responsabilidad de un delito (Hans-Hermann Hoppe, 2004:87-95), es decir, sobre el actor podría recaer la responsabilidad del acto dependiendo de su "intención" y de la "causalidad". Esta concepción de responsabilidad es contraria al pensamiento desarrollado por Rothbard, el cual únicamente consideraba la causalidad como fuente de responsabilidad del delito.

IV

REDARQUÍA

Redarquíaes un término acuñado por José Cabrera (2014) que utilizó para definir el nuevo orden emergente en las comunidades colaborativas. Citándole: "Creo sinceramente que los modelos mentales que hoy sostienen nuestras organizaciones van en la dirección equivocada. No nos están ayudando a crear valor. Cuanto más nos aferramos a las jerarquías tradicionales, más nos alejamos de las enormes posibilidades que nos brinda la nueva era de la colaboración para crear organizaciones ágiles y flexibles, donde podemos dar lo mejor de nosotros mismos y crear valor económico y social de forma sostenible. El hecho es que no podemos enmarcar la realidad actual utilizando las estructuras jerárquicas tradicionales, 
sencillamente porque son piezas que no encajan. Tampoco podemos seguir empeñados en aplicar soluciones que, si bien fueron oportunas en su día, surgieron para resolver problemas que ya no son centrales para avanzar hacia el futuro"12.

La idea de pérdida de jerarquía en las empresas explicada por Cabrera, se utilizará en este análisis en referencia a la pérdida de jerarquía en la forma de organización social.

Partiendo de esta base, trataremos de desarrollar un análisis prospectivo de posibles formas de organización social pro-iusnaturalistas, las cuales aprovecharían el potencial de Internet, debido a su rápido alcance y su alta disponibilidad en sociedades capitalistas avanzadas, y hará uso de los conocimientos sobre recopilación, análisis, procesado y verificación de información actuales.

Sin duda alguna, las tres formas propuestas tendrían un carácter ex post, por lo que, una vez reunida y analizada, la información podría utilizarse para intentar prevenir la delincuencia y aumentar el sentimiento de pertenencia a una comunidad, perdiendo gradualmente la jerarquía estatal con una sociedad más intercomunicada y horizontal.

De esta manera, estableceríamos una comunidad redárquica o comunidad de información sensible verificada, cuyo origen informativo sería la ciudadanía y las empresas, siendo el receptor/decisor final, igualmente, los ciudadanos y las empresas.

Teniendo en cuenta todo esto, junto con el código ético del apartado anterior, se han estructurado las siguientes formas/instrumentos iusnaturalistas que podrían surgir según su grado de implantación y presencia (teniendo en cuenta la relatividad moral en cuanto a la privacidad), utilizando Internet como medio.

\section{Comunidadredárquicadegradol:geolocalización dedelitos}

Este primer tipo de sociedad partiría de una plataforma web/aplicación con un mapa interactivo en el cual el ciudadano agredido pueda compartir que, en un punto del mapa y a una hora determinada, ha

12 Para más información: http//blogs.cincodias.com/inteligencia-competitiva a fecha del 13 de agosto de 2014. 
sufrido una agresión. De esta manera, a todo el mundo le aparecerán cuales serían las zonas más seguras, aumentando la prevención ciudadana y permitiendo, así, destinar recursos para mejorar la seguridad de manera más eficaz y eficiente.

Dicho mapa podría establecer una serie de filtros de los crímenes, para que el usuario pueda seleccionar que le aparezcan aquellos que le son de más interés. Además, se podría seleccionar que se muestre un intervalo de tiempo determinado para que así se vea que unos tipos de delitos son más frecuentes a una hora o un día específicos.

Sería recomendable que, a la hora de compartir un crimen, la web tenga dichos crímenes programados de manera predeterminada para que, si el usuario quiere cambiar el idioma, se puedan cambiar automáticamente dichos botones al idioma correspondiente, y para que el usuario pueda filtrar los crímenes según unos parámetros establecidos.

Evidentemente, cuando un usuario navegue por el mapa, podría informarse más del caso en cuestión clicando en un punto/ delito determinado.

Sería recomendable, a la hora de geolocalizar un crimen, señalar si has sido el agredido o si eres un testigo ${ }^{13}$. De esta manera, se evitarían multitud de duplicidades de puntos y ayudaría a ver el volumen real de delitos que se comenten y a aumentar la verificación de dichos actos.

Debido a la sensibilidad del tema, es altamente aconsejable que todos los usuarios que compartan la información sean anónimos.

Otro uso útil que se le podría dar sería el de un sistema de avisos inmediato al usuario, el cual previamente ha seleccionado la zona y delitos específicos sobre los que quiere que le avise. Además, el usuario podría utilizar otra opción: que se le avise de si se ha cometido un crimen en un radio de $X$ metros con respecto a su posición. Esto, sin duda, aumentaría la tranquilidad y actuación ciudadana en momentos clave, en los que el tiempo es vital para poder identificar al delincuente.

13 También podría ser al más puro estilo Waze, cualquiera puede compartir en el mapa que un crimen ha sido cometido en un lugar y tiempo determinados y que el resto de usuarios pueda valorar dicha información compartida con botones de "fiable" o "no fiable", algo que considero mucho más eficaz y eficiente. 
Este sistema sería mucho más efectivo que otros hoy en uso ya que, los ya existentes, 1) se basan en los arrestos policiales y no en el lugar del crimen y 2) son sacados de bases de datos policiales, por lo que muchos crímenes se quedan sin saber porque mucha gente no suele denunciar. Además, perdería su carácter de inmediatez si hay que esperar a que vaya la policía a un sitio y tenga que compartirlo en el mapa ${ }^{14}$.

La prevención sería la principal característica básica de este tipo de comunidad, aunque, como hemos mencionado, podría dársele un uso más inmediato a la hora de mejorar la seguridad de una región. Evidentemente, este método está limitado a delitos que puedan ser localizados en un mapa, excluyendo aquellos que se realizan por Internet, o tienen una naturaleza distinta.

\section{Comunidad redárquica de grado II: la lista negra}

Atendiendo al derecho de boicot, o libertad de decisión, ya mencionado anteriormente, este segundo grado correspondería al desarrollo de una macro-lista negra de delitos morales, en la cual los ciudadanos puedan denunciar quién ha cometido un delito. Evidentemente, sería necesaria una identificación de la persona agresora en cuestión. Esta información revelada podría entrar en conflicto con la privacidad de las personas, pero es necesario que nos planteemos que, si al igual que en un intercambio hay una información que es inevitable ceder, cuando cometes un crimen moral, te expones a perder dicha información que revela tu identidad y/o a una posible investigación posterior para probar tu culpabilidad o inocencia.

Lo óptimo sería que los administradores de listas negras actuasen como "verificadores" sobre si ciertas variables (causalidad e intención) han sido cumplidas por una persona concreta, para determinar, así, si es responsable o no de una acción. Tanto denunciante como denunciado podrán presentar pruebas que ayuden a

14 Algunos sitios web de temática parecida: crimemapping.com, trulia.com, crimereports.com, spotcrime.com y blenditbayes.shinyapps.io 
decidir a los verificadores sobre si poner al denunciado en la lista o no (dependiendo de la responsabilidad sobre el acto).

Cuando se habla de una macro lista negra, en realidad, no se refiere a que solo deba existir una. De hecho, para que pueda funcionar bien este método es necesaria la competencia entre verificadores, para que, así, se vean "obligados" a no ser corruptos y actuar diligentemente.

Si se diese una situación de monopolio, habría muchos incentivos para que no actuasen conforme a lo que se espera de ellos, con la pérdida consecuente de confianza ${ }^{15}$. No interesa que se mienta ya que, una "justicia" en la que no se puede confiar, no es "justicia". Este, sin duda, es uno de los principales problemas del sistema de justicia actual, debido al monopolio estatal en esta materia. Eliminando el filtro y fuerzas de la competencia, es irremediable que se acabe actuando de forma corrupta e ineficaz, perdiendo cada vez más la confianza depositada en estos proveedores de servicios sin poder tener una alternativa real.

Además, cada lista debe realizar sus servicios de verificación siguiendo su propio código. De esta manera, podría surgir una lista basada en un código ético como el que proponemos en este trabajo, otra en la que se oriente a animales, otra sobre explotación laboral, orientada al medio ambiente, etc. Incluso, podrían llegar a surgir listas más específicas que atañan a diversas controversias morales como el trabajo infantil, derechos de los animales, violencia policial/estatal, etc. tendiendo a aquello que le correspondería a la ley natural ${ }^{16}$.

Lo más interesante de este método es que ya se está empezando a instaurar en una materia particular: el riesgo de impago o morosidad. Han surgido empresas como RAI o ASNEF, las cuales recogen datos de bancos y demás empresas que tienen deudores que no les pagan y les incluyen en sus bases de datos. Posteriormente, si una empresa quiere saber si un cliente tiene un riesgo alto o bajo, lo consultará en dichas bases de datos.

15 Como bien expone Juan Ramón Rallo en su artículo sobre la mentira [En línea] (2014): ¿Es la mentira como la carne podrida? vozpopuli.com

16 Incluso podrían surgir listas que tengan el mismo código ético, aumentando la competitividad en eficacia y eficiencia entre ambas compañías. 
Además, atendiendo al derecho de boicot, están surgiendo "contra-boicots" a dichas empresas de rating, como las campañas de FACUA en contra de las altas penalizaciones por no pagar a tiempo.

Incluso el Estado español está utilizando este mismo método para sacar a la luz la lista de defraudadores de impuestos, para que posteriormente se aplique un "castigo social"17.

En Canadá, cada vez está más extendido el hecho de que las empresas pidan el certificado de penales a aquellas personas que vayan a trabajar con ellas, lo cual es un gran incentivo para el ciudadano a la hora de no cometer ningún delito o hacer más difícil la vida a los delincuentes. En este caso, el proveedor de la lista es el Estado canadiense, además de ser el único que tiene potestad para decidir a quién otorgar el indulto (no es el denunciante el que perdona al condenado) y hacer "borrón y cuenta nueva" en el historial del delincuente.

Un ejemplo de verificadores no estatales serían los prestadores de servicios de certificación SSL, como VeriSign, los cuales han llegado a donde están al ganarse la confianza de sus clientes a la hora de dar fe de que los intercambios de claves asimétricas (público-privadas) se realizan por Internet de manera segura. El fin de estos notarios de intercambios sería el de asegurar que $A$ y $B$ son los únicos que puedan acceder a una información que se intercambia vía web en un momento determinado. Un ejemplo visual puede ser la verificación entre la web de un banco y un cliente que quiere acceder a la información de su cuenta.

La forma del castigo social de la lista negra sería el aparecer en la lista negra y que se pueda saber quién eres y/o qué es lo que has hecho, propio del boicot. Tras aparecer en la lista negra, se podrían derivar varios comportamientos, algunos de ellos serían:

- Los consumidores/empresas no comprarían (o no comprarían tanto) a empresas que aparezcan en listas negras ${ }^{18}$.

17 Para acceder a la lista de contribuyentes morosos: dgt.hacienda.go.cr

18 Una situación que llamó la atención, en verano de 2014, fue la aparición de listas con los comercios judeo-israelíes de Roma, para concienciar a la gente de que no les comprasen. Al margen del carácter antisemita y de ser una generalización apresurada (tipo de falacia), la forma de la iniciativa (lista negra) entraría dentro de los parámetros 
- Laspersonas quebuscan empleotenderían a aceptar antes a empresas que no salgan en dichas listas.

- Los empleadores pagarán menos o directamente no contratarán a gente de la lista.

- Las empresas cobrarán más, o directamente no venderán, a aquellos que aparezcan en la lista.

Atendiendo a los posibles comportamientos, tenderíamos a actuar lo más moralmente posible para evitar aparecer en dichas listas y que no se realice el castigo social. Así mismo, para asegurarse que los denunciantes no intentan culpar a alguien inocente de algo que no ha hecho, el administrador de la lista debería abrir un apartado para aquellos que les han mentido, dejando que sea la misma sociedad la que juzgue moralmente a esos mentirosos. De esta manera, aquellos que intenten acusar en falso a alguien se lo pensarán antes de actuar.

Evidentemente, con el paso del tiempo, un denunciante puede solicitar que su agresor desaparezca de la lista porque ya considera que ha tenido suficiente "castigo" y, por lo tanto, se considere perdonado.

Sería conveniente que, en aquellos casos en los que el delito moral se ha realizado en situaciones de emergencia, se marque de manera especial dicho caso para que los usuarios sepan que el verificador le dota de una característica especial que puede ser muy valorable moralmente.

Finalmente, conviene destacar que, poco a poco, tal vez debido a la menor eficiencia y eficacia de la justicia y a un relativismo moral imperante, el orden extenso está intentando canalizar esas necesidades de "justicia" en forma de listas negras. Esto se debe principalmente a que entran dentro de los parámetros éticos generales de la mayoría de las personas y, de momento, no quebranta gravemente el código iuspositivista vigente ${ }^{19}$.

morales, ya que se alude al derecho de boicot (pacífico) y al poder elegir dónde comprar. Más información en: Lista negra de comercios judíos en Romapor A.G. Fuentes para abc.es el 11 de agosto de 2014

${ }^{19}$ Aquellas listas negras que no tengan la figura del "verificador" sí que podrían entrar en problemas legales (derivados del derecho positivo) como el artículo 24 de la 


\section{Comunidad redárquica de grado III: la lista negra 2.0}

Este tipo de comunidad conlleva una implicación y tecnología mucho mayor que la del grado II. En sí, consistiría en la unión de un dispositivo electrónico de identificación personal (ej.: DNI, tarjeta bancaria, etc) el cual, cuando lo pasas por un lector, te busca entre las distintas listas negras y permite saber al instante el delito que has cometido.

El uso principal sería el siguiente: en caso de compra, permitir al vendedor la identificación inmediata de su cliente, incluyendo su aparición o no en alguna lista negra. Conforme a los delitos morales del comprador, el vendedor podrá decidir si cobrarle más o menos por su compra o incluso negarse a venderle.

Imaginemos que hay una gran base de datos de delitos morales y que cada individuo de una sociedad tiene una tarjeta electrónica con su identidad guardada. En una función especial de la web administradora de la base de datos, el dueño de un comercio puede parametrizar una serie de filtros que quiera aplicar según su moralidad. En dichos filtros podría poner que, por ejemplo, a los que hayan robado entre 0 y 2000 euros les cobrará $x 4$ del precio final, entre 2 000 y 100000 les cobraráx20, y a partir de 100000 no les venderá. Así mismo, teniendo en cuenta la relatividad moral, se podría filtrar cada persona individualmente, es decir, si "José Pérez" ha robado 1 000 euros, podría excluirle sólo a él específicamente de ese filtro y asignarle otra pena distinta (que en vez de $x 4$, que sea $x 2$ cuando robas hasta 2000 euros) 0 , incluso, quitarle la pena.

Posteriormente, cuando se está vendiendo en la tienda, antes de que salte el precio (o de pasar los bienes que se vayan a comprar), el comprador deberá pasar la tarjeta para que se empiece a aplicar el filtro previamente establecido. Evidentemente, si José Pérez pasase por allí, a la hora de pagar tendría que desembolsar el doble que una persona que no esté en la lista.

Otra opción de utilización de estas tarjetas sería, en vez de pasar la tarjeta en caja, tener que pasarla en la entrada de un

Constitución Española (1978), atendiendo al derecho de un juicio justo, derecho a la defensa, suposición de inocencia, etc. En la Unión Europea también entraría en juego la Ley de Protección de Datos. 
establecimiento, véase un concierto, una discoteca, estadio o un centro comercial. Si antes de entrar pasas la tarjeta, teniendo en cuenta la moralidad del dueño del recinto (el cual previamente ha establecido ciertos parámetros morales para entrar, como este: "todos los de la lista pueden pasar menos los asesinos"), podrás entrar o no, debido al derecho de admisión.

Una característica que podría ser útil, podría ser que el sistema ofreciese un filtro de los delitos que se han cometido en una franja de edad. Pudiera ser que una persona A cometió un robo de 500 euros a los 12 años. Persona B, dueño de un local, cree que una persona entre 0 y 12 años no es lo suficientemente madura y, por eso, discrimina en la lista aquellos delitos que se hayan cometido entre esos años.

Otra opción adicional sería poder establecer algunos filtros de manera temporal, es decir, si A ha cometido un robo de 3000 euros, $\mathrm{B}$ le castigue con precios $\times 20$, pero sólo durante un tiempo determinado (ej.: 3 años desde la aparición en la lista negra). Otra opción sería que se pongan filtros de manera escalonada con el paso de determinado tiempo, ej: al cabo de 3 años $x 15$ y de 10 años $x 5$.

Actualmente, la opción más recomendable, aunque también la más costosa, es la opción de las tarjetas de contacto $\mathrm{TCI}$, como el $\mathrm{DNI}$ electrónico ${ }^{20}$, ya que permite un sistema de identificación a través de Internet bastante más fiable al necesitar el chip físico para poder realizar una operación manteniendo la integridad y seguridad de la información.

\section{$\mathrm{V}$ \\ EL PAPEL DE LA EMPRESA Y CONSUMIDOR COMO AGENTES SOCIALES}

Cuando se habla de empresas éticas solemos pensar que es un oxímoron, o términos que no van nunca juntos, pero lo cierto es que,

20 El nuevo DNI electrónico instaurado en 2015, aunque tiene la propiedad de no ser de contacto, y por lo tanto ser más eficiente, lo cierto es que pierde cierto grado de seguridad (siempre que sea inalámbrico será mucho menos seguro que siendo de contacto). Se tiene que barajar ese punto entre más seguridad o más eficiencia. Esto aplica de la misma manera con la tecnología NFC. 
cada vez más, hay una tendencia marcada hacia la importancia de actuar éticamente en los negocios, convirtiendo su propio código ético en el leitmotiv, o misión, de la empresa. Dicha tendencia se recoge muy bien bajo el término, acuñado por Kotler, Marketing 3.0, ya que recoge el concepto de cómo una conducta ética plasmada en la misión de cada empresa puede influir en su supervivencia futura en un contexto incierto y de constantes cambios.

Hace mucho tiempo, durante la era industrial, la estrategia empresarial consistía en vender lo producido por las fábricas a todo aquel que estuviera dispuesto a comprarlo. Los productos eran bastantebásicos y estaban diseñados para atenderlas necesidades deun mercado de masas. Era la era del producto como centro del sistema.

La competencia empresarial 2.0 surge en la actual era de la información, basada en las tecnologías de la información. La tarea del empresario ya no es tan sencilla. Los informadores de hoy están bien documentados y pueden comparar fácilmente diversas ofertas de productos similares. Es el consumidor quien define el valor del producto. La empresa debe segmentar el mercado y desarrollar un producto superior para un segmento específico. Ésta perspectiva correspondería con la era orientada al consumidor.

Actualmente estamos presenciando la etapa empresarial 3.0, o el inicio de una nueva era centrada en los valores. En lugar de tratar a las personas como simples consumidores, las empresas los conciben como seres humanos, con inteligencia, corazón y espíritu. Cada vez más, los consumidores buscan soluciones para preocupaciones sobre cómo convertir este mundo globalizado en un mundo mejor. En un entorno lleno de confusión, buscan empresas que tengan presente en su misión, visión y valores sus necesidades más profundas de justicia social, económica y/o medioambiental. Al elegir productos y servicios pretenden una satisfacción espiritual, y no meramente funcional o emocional. Así mismo, las empresas se empiezan a diferenciar entre sí por sus valores. En tiempos turbulentos la diferencia en este aspecto entre unas y otras puede resultar considerable (Philip Kotler, 2011:19-21).

Esta teoría basa su fundamento en: la realidad que estamos viviendo sobre el aumento de la participación de los consumidores, a la hora de involucrarse en las empresas (marketing de colaboración, como pudieran ser los crowdsourcing o colaboradores 
masivos para encontrar nuevas ideas); la tendencia hacia una era de sociedad creativa (marketing espiritual), la cual representa el mayor nivel de desarrollo social en la civilización humana, siendo la tecnología la principal fuerza impulsora de esta evolución (Daniel Pink, 2005). La sociedad creativa está aumentando su influencia por todo el mundo, ya que intentan permanentemente progresar y mejorar el mundo en el que viven, convirtiéndose así en la espina dorsal de la economía de los países avanzados.

A medida que el número de personas creativas aumenta en los países desarrollados y en vías de desarrollo, la civilización humana avanza. Una de las características clave de una sociedad avanzada y creativa consiste en que la gente cree en la autorrealización más allá de sus necesidades básicas de supervivencia. Se trata de individuos expresivos y que colaboran entre sí en los procesos de creación común. Como seres humanos complejos que son, confían en la parte espiritual del individuo y saben escuchar sus deseos más profundos (Philip Kotler, 2011:36)

Hoy en día, la confianza se da más en las relaciones horizontales que en las verticales. Los consumidores confían más los unos en los otros que en las empresas. El auge de los medios sociales no es más que el reflejo de la migración de la confianza de los consumidores desde las empresas hacia los demás consumidores. Si bien el consumidor individual es débil, el poder colectivo de los consumidores siempre será mayor que el de cualquier empresa. Es notable la cantidad de empresas que surgen basadas en la colaboración, o que fomentan una horizontalidad y mejor aprovechamiento de los recursos que se disponen, como pueden ser Wikipedia, Ebay, Wallapop, Blablacar, etc e incluso otras no tan orientadas a la gestión de recursos como la aplicación Waze.

De esta manera, encontramos en esta concepción de confianza la principal base para desarrollar el fundamento de las comunidades redárquicas propuestas anteriormente, las cuales promueven una sociedad horizontal, estableciendo una alternativa factible al sistema actual, basado en relaciones verticales. Así, surge una suerte de Redarquía en la que la jerarquía estatal va desapareciendo poco a poco, sustituyéndose por una red horizontal conforme a los valores éticos. Es por ello que, la forma adecuada para la figura del verificador, debería ser la de Empresa. 
Sin duda alguna, desde el punto de vista filosófico, el concepto Hegeliano de Estado, podría aplicársele a este tipo de asociaciones, pues para ello deben surgir como forma de la voluntad. Sin embargo, Oakeshott detecta que, en Hegel, toda aquella forma de organización que esté formulada en términos de qua empresa, y que tendría por lo tanto sus raíces en las prácticas prudenciales exclusivamente, no ha de ser calificada como Estado, siendo para él objeto de recelo ${ }^{21}$ (López Atanes, 2010: 104).

Caracterizando al Estado como "unión de personas con múltiples conductas libremente elegidas y que se asocian para defender ese concreto modo de vida frente al colapso interno o la agresión externa", no se sabe muy bien si al final los modelos de comunidad propuestos entrarían dentro del marco conceptual de Estado.

Es interesante como ha derivado la concepción de Estado hacia un gobierno cada vez más teleocrático, caracterizado por una intensa actividad legislativa, intensa respecto al nivel tan especifico al que se detallan, pero intensa también por su voracidad. Llega, así, a acaparar casi todas las áreas posibles y regular casi todos los aspectos de la vida humana, a fin de responder con mayor eficacia a un supuesto fin del gobierno.

Esta concepción del Estado es solo posible porque está alimentada por una antropología social subyacente que reduce al individuo a la masa. Dicho hombre-masa renuncia a la libertad, renuncia a su derecho de elección y deja que otro tome por él las decisiones que él por sí mismo no puede adoptar, entre otras razones, porque ya no hay persecución de intereses individuales (por cada individuo) sino imposición de uno colectivo (Ortega y Gasset, 2013).

Todo esto hace que nos preguntemos entonces, ¿cómo es posible que exista la libertad humana, si todo está sometido a una inexorable regulación permanente? Por un lado, Spinoza afirma un determinismo (negación de la libertad humana) riguroso, aunque deja

21 Citando a Oakeshott (2001), dentro del análisis de López Atanes F.J. (2010), sobre la denominación de asociación qua empresa: "Según esto, no serían personas relacionadas en torno a una confesión religiosa o una llamada conciencia nacional, al amor, a la virtud o a las directrices de un administrador señorial y de sus agentes. Tampoco serían asociaciones para la protección, promoción o reconciliación de los intereses de los individuos en su afán por satisfacer necesidades contingentes." 
el resquicio de una definición poco alentadora y paradójica de libertad: la libertad humana aparece cuando el ser humano acepta que todo está determinado. Para él, la libertad no depende de la voluntad sino del entendimiento, el hombre se libera por medio del conocimiento intelectual.

Además, Spinoza afirma que existen leyes universales de la Naturaleza a las que los hombres están sujetos, por lo que no se puede afirmar que el hombre es totalmente libre. Según su visión, el fin del Estado es hacer a todos los hombres libres, lo que significa que el hombre ha de dejar de ser un autómata. En contraposición, Rousseau desarrolló un esquema social, en el cual el poder recae sobre el pueblo, argumentando que es posible vivir y sobrevivir como conjunto sin necesidad de un último líder que fuese la autoridad (Spinoza, 2011).

En El Contrato Social, Rousseau argumenta que el poder que rige a la sociedad es la voluntad general que mira por el bien común de todos los ciudadanos. Este poder sólo toma vigencia cuando cada uno de los miembros de una sociedad se une mediante asociación bajo la condición de que "Cada uno de nosotros pone en común su persona y todo su poder bajo la suprema dirección de la voluntad general; y cada miembro es considerado como parte indivisible del todo" (J.J. Rousseau, 1964:361).

Rousseau plantea que la asociación asumida por los ciudadanos debe ser "capaz de defender y proteger, con toda la fuerza común, la persona y los bienes de cada uno de los asociados, pero de modo tal que cada uno de estos, en unión con todos, sólo obedezca a sí mismo, y quede tan libre como antes". La moral y la razón se hacen evidentes en la sociedad al establecer un modelo normativo capaz de crear un orden social que evite la dominación de unos sobre otros y que involucre una representación participativa de todos los miembros de la sociedad.

De esta manera, Rousseau considera que toda aquella persona que participe del contrato social es soberana, y por ende es un bien común el que se obtiene a través de este contrato. Por esta razón no puede existir una distinción entre soberano e individuo y se debe legislar bajo la voluntad general. Según él, este tipo de gobierno comienza una vez el pueblo ha madurado moral y políticamente para lograr comprender e implementar la voluntad general, y que ésta sea libre de interferencias. 
Sin embargo, tras este último apunte, su argumento entra en una contradicción en sí misma ya que, por un lado, dice que hay que evitar la dominación de los unos sobre los otros, pero, por otro, que la voluntad del conjunto de la población sí "domine" a la población en sí misma, es decir, que el individuo se someta a la voluntad de la mayoría (voluntad general).

Si atendemos al pensamiento de la Escuela de Salamanca, la garantía de libertad se ve correlacionada con la defensa de la propiedad privada, principalmente desarrollada por Luis de Molina. Al margen de que, para él, la creencia de que la propiedad privada quedaba justificada con el mandamiento "no robarás", fue más allá diciendo: "Cuando la propiedad sea común, no se cuidará y la gente luchará por consumirla". Es así que, lejos de promover el bien público, cuando la propiedad no se divida, las personas fuertes del grupo se aprovecharán de las débiles monopolizándola y consumiendo todos sus recursos. De esta manera concluye que, quienes se beneficien, estarían obligados por ley moral a compensarlos daños que causan²2 (Rockwell, 1995:546).

Es interesante también su aparente dualidad de pensamiento, ya que por un lado pensaba que la propiedad común garantizaría el fin de la generosidad y caridad, y por otro, que "las limosnas deberían darse a partir de los bienes privados y no de los comunes"

En resumen, podemos concluir que la libertad es un bien esencial, la condición de existencia de la vida moral (tanto desde el plano ontológico como epistemológico), la cuestión está en si es el Estado el que proporciona la garantía de esa libertad o si, por el contrario, lo único que hace es crecer la masa, y, por lo tanto, conseguir el efecto contrario: que el individuo pierda su libertad. De esta manera, se podría pensar que otro tipo de asociaciones (comunidades redárquicas) pudieran surgir como mejores garantes de libertad, o que incluso ni siquiera éstas sean necesarias a la larga.

Finalmente, como ya se ha mencionado, la denominación de las comunidades redárquicas debería tomar la forma de empresa debido a

22 Es interesante también su aparente dualidad de pensamiento, ya que por un lado pensaba que la propiedad común garantizaría el fin de la generosidad y caridad, y por otro, que "las limosnas deberían darse a partir de los bienes privados y no de los comunes". 
un factor diferenciador del Estado, la competencia. Un Estado no permitiría la competencia con otros Estados dentro de su mismo territorio, mientras que el modelo de sociedad propuesto toma como requisito el factor de la competencia como medida esencial para evitar los abusos que pudiese causar un monopolio. Ahora bien, es cierto que un Estado actual podría competir con dichas empresas añadiendo un servicio de listas negras pagado con el dinero de los contribuyentes, pero ahí se dependería de la tolerancia del decisor político de turno, a la hora de perder poder, y de la concepción moral-inmoral de los impuestos ${ }^{23}$.

$\mathrm{VI}$

\section{CONCLUSIONES}

Llegados a este punto, se puede concluir que una sociedad basada en los distintos tipos de comunidades redárquicas propuestos, puede ser factible a la hora de traer estabilidad al orden extenso. Dicha estabilidad sería causada por una mayor involucración de la sociedad en materia de la seguridad, incremento de los valores morales, mayor sentimiento de pertenencia a la sociedad (más acogedor y menos desconfiado) derivando en una mejora, a largo plazo, de la calidad de vida de los ciudadanos.

Es cierto que la implantación de un sistema que puede llegar a ser sustitutivo directo de los servicios iuspositivistas estatales puede traer ciertas inestabilidades internas dentro de la sociedad, debido principalmente al carácter monopolístico del Estado, cuyo decisor político no estará por la labor de perder poder.

Si se empiezan a desarrollar este tipo de comunidades, el problema surgiría cuando se valore y confíe más en la forma de justicia iusnaturalista propuesta, basada en las redes informales de la sociedad, que en la iuspositivista, puesto que sería algo que haría plantearse la mismísima esencia del sistema judicial en el que vivimos.

$23 \mathrm{Si}$ un Estado realiza una lista negra de robos, la gente podría pedir que metiesen al propio Estado en la lista, al sustraer éste su dinero de manera involuntaria (en el caso de impuestos involuntarios) yaque, hay personas que podría catalogar la esencia de los mismos como un robo. 
Además, es concluyente que actualmente no estamos preparados ni tecnológicamente, ni moralmente, para afrontar este tipo de cambios. Tal vez en algunos reductos de la sociedad pueda ser factible la implantación leve de estos métodos, debido a una mayor educación en valores. A nivel tecnológico, de momento no se puede desarrollar globalmente, ya que en muchas regiones no llega siquiera Internet o incluso si llegase, son muy pocos los países que tienen documentos de identidad tipo $\mathrm{TCl}$ (u otra base tecnológica desde la que partir).

Sin embargo, esto no significa que en un futuro (cercano o lejano) no pueda desarrollarse el soporte básico para este tipo de sociedades, algo que, intencionadamente o no, va en dicho camino. A fin de cuentas, setenderáaaquelloqueseaacordealoquedebeserdecadaépoca, es por eso que, teniendo en cuenta que nunca antes hemos estado tan conectados, gracias a Internet, es necesario pensar fuera de nuestra zona de confort y estar abiertos a nuevas concepciones de organización de la sociedad posiblemente más acordes a nuestro tiempo.

\section{REFERENCIASBIBLIOGRÁFICAS}

Block, Walter (2008). Defending the Undefendable. 1aㅡ Edición. Editorial LvM Insitute.

Bondone, Carlos A. (2006). Teoría de la Relatividad Económica. Edición online.

Cabrera, José (2014). Redarquía: Más allá de la Jerarquía. Editorial Redarquía.net

Confucio (2014). Los Cuatro Libros. Editorial Orientalia.

Garrido, Vicente; Stangeland, P.; Redondo, Santiago (2006). Principios de la criminología. $3^{a}$ Edición. Editorial Tirant lo Blanch.

Gómez Fuentes, Ángel [En línea] (2014). Lista negra de comercios judíos en Roma. Diario ABC. Abc.es [11/08/2014].

Hayek, F.A. (2008). Camino de Servidumbre. Edición definitiva. Unión Editorial.

- (2010). La Fatal Arrogancia. 3를 Edición, 2ª reimpresión. Unión Editorial.

Hesseling (1994). Displacement:a Review of the Empirical Litterature, in R.V Clarke (ed.) Crime Prevention Studies 3. Monsey NY: CriminalJusticePress. 
Hoppe, Hans-Hermann (1995). «The Political Economy of Monarchy and Democracy, and the Idea of a Natural Order». Journal of Libertarian Studies. Vol. 11:2, pp. 94-121.

- (2004). «Property, Causality, and Liability». The Quarterly Journal of Austrian Economics. Vol. 7 no 4, pp. 87-95.

Kotler, Philip; Kartajaya; Setiawan (2011). Marketing 3.0. 1ª Edición. LID Editorial.

López Atanes, Francisco Javier (2010). Conducta Humana y Sociedad Civil:Introducción ala Filosofía Políticade M. Oakeshott. $1^{\text {a}}$ Edición. Unión Editorial.

Mises, Ludwig Von (2011). La Acción Humana. 10ª Edición. Unión Editorial.

Oakeshott, M. (2001). El Estado Europeo Moderno. Barcelona. Paidos.

Ortega y Gasset, José (2013). La Rebelión de las Masas. 4ª Edición. Editorial Austral.

Pink, Daniel H. (2005). A Hole New Mind: Moving from the Information Age to the Conceptual Age. 1를 Edición. Editorial Riverhead Books.

Rallo, Juan Ramón [En línea] (2014). “¿Es la mentira como la carne podrida?" para vozpopuli.com [10/07/2014].

Repetto (1976). "Crime prevention and the displacement phenomenon». CrimeandDelinquency. Vol.22.

Rockwell, Jr (1995). "Free Market Economists: 400 years ago". The Freeman. Pp 544-547.

Rousseau, J.J. (1964). Du Contrat Social ou Principes du Droit Politique. Oeuvres completes. Dijon: Gallimard.

Rothbard, Murray N. (2009). La Ética de la Libertad. 2ª Edición. Unión Editorial.

- (2013). El Hombre, la Economía yel Estado Vol.2.1 1Edición. Unión Editorial.

- (2000). «War, Peace, and the State». Libertarian Review Press. Pp. 115-132.

Shaw, Margaret (2011). Manual sobre la aplicación eficaz de las Directrices para la prevención del delito. Centro Internacional para la Prevención de la Criminalidad, Oficina de las Naciones Unidas contra la droga y el delito.

Spinoza Baruch (2011). Ética: demostrada según el orden geométrico. Edición de Vidal Peña. Alianza Editorial. 
Stangeland, P.; Díez Ripollés, Durán (1998). El blanco más fácil: la delincuencia en zonas turísticas. $1^{\text {a }}$ Edición. Editorial Tirant lo Blanch/IAIC

Zafra, Juan M. [En línea] (2014). “Nuevas estructuras organizativas en la Era de la Colaboración: Redarquía." Blog de Inteligencia Competitiva de CincoDías. blogs.cincodias.com/inteligencia-competitiva [13/10/2014]. 